\title{
MUTACIÓN EN LOS CRITERIOS JURISPRUDENCIALES DE PROTECCIÓN DE LOS DERECHOS A LA SALUD Y AL TRABAJO EN CHILE
}

\author{
MUTATION OF JURISPRUDENTIAL PROTECTION CRITERIA FOR THE \\ RIGHTS TO HEALTH CARE AND LABOR IN CHILE
}

\author{
Jaime Bassa Mercado* \\ Bruno Aste Leiva*
}

\begin{abstract}
RESUMEN: El contenido normativo de los derechos fundamentales se estructura desde enunciados abiertos e indeterminados, cuya concreción requiere de una labor interpretativa. La reciente jurisprudencia constitucional de derechos sociales, concretamente respecto a los derechos a la salud y al trabajo, presenta una mutación en su comprensión tradicional, ampliando su ámbito de protección constitucional a través de nuevos criterios de interpretación.

Palabras clave: Constitución. Mutación. Derechos sociales. Interpretación constitucional.

ABSTRACT: Fundamental right's normative content is structured within indeterminate dispositions, which concretion requires an interpretative exercise. Recent constitutional jurisprudence on social rights, specifically on the rights to health care and labor, presents a mutation on its traditional conception, amplifying its constitutional protection through new hermeneutic criteria.
\end{abstract}

Key words: Constitution, Mutation, Social Rights, Constitutional, interpretation.

\section{INTRODUCCIÓN}

La presente investigación tiene por objetivo verificar si se ha producido un cambio en los criterios de protección de los derechos sociales a la salud y al trabajo, a partir de la última jurisprudencia emanada del Tribunal Constitucional en la materia. Se propone como hipótesis que se ha verificado una mutación constitucional en el contenido material de los derechos fundamentales señalados, precisamente por los nuevos criterios que el Tribunal Constitucional chileno ha tenido a la vista al resolver conflictos sometidos a su conocimiento. De esta forma, se revisarán los criterios más tradicionales de protección de estos derechos, especialmente aquellos que determinaron su contenido normativo en los prime-

\footnotetext{
Licenciado en Derecho por la U. Católica de Chile. Magíster en Derecho, mención en Derecho Público, U. de Chile. Doctor en Derecho, U. de Barcelona, España. Profesor de Derecho Constitucional, Escuela de Derecho, Universidad de Valparaíso y Coordinador del Núcleo de Investigación Derecho y Ciudadanía, de la misma Universidad. Dirección postal: Av. Errázuriz 2120, Valparaíso, Chile. Correo electrónico: jaime.bassa@uv.cl. Este artículo es parte del proyecto Fondecyt $\mathrm{N}^{\circ} 11110290$.

" Licenciado en Derecho, Universidad Viña del Mar. Abogado. Profesor de Derecho Constitucional de la Universidad de Antofagasta y miembro del Núcleo de Investigación Derecho y Ciudadanía de la Universidad de Valparaíso. Dirección postal: Av. Universidad de Antofagasta 02800. Antofagasta. Chile. Correo electrónico: bruno.aste@uantof.cl
} 
ros años de vigencia de la Carta y que estuvieron vigentes por décadas mediante la aplicación de criterios originalistas de interpretación constitucional. El progresivo abandono de estos criterios permite explicar, en parte, la mutación en el contenido de los derechos, configurado por la interpretación constitucional.

\section{LA MUTACIÓN CONSTITUCIONAL COMO GARANTÍA DE LIBERTAD POLÍTICA}

\section{A. La mutación CONSTITUCIONAL}

El término refiere a los cambios que se producen en el ordenamiento constitucional al margen de los procedimientos formales de reforma, en virtud de los cuales se afecta la realidad constitucional en forma inconsciente o no intencionada ${ }^{1}$. Aunque es posible abordar el concepto desde diversas perspectivas más o menos críticas ${ }^{2}$, la mutación permite comprender uno de los fenómenos que ha experimentado la Constitución chilena en las últimas dos décadas: junto a una serie de reformas, se aprecia un proceso de democratización que va más allá de ellas, que cambia el sentido originalmente atribuido a las normas constitucionales.

A pesar que solo es jurídicamente vinculante la norma positiva ${ }^{3}$, el Estado rebasa el entramado de normas positivas que lo constituye. Junto al ordenamiento normativo, existe una compleja red de relaciones materiales de poder político que sitúan al Derecho en una permanente tensión relacional junto a lo político. Así, el fenómeno también se entiende a través de la realización cultural tras la tensión dialéctica entre individuo y Estado, la que renueva permanentemente los diversos elementos que lo componen ${ }^{4}$. Las fuerzas políticas que, desde la sociedad, empujan la permanente transformación de los contenidos constitucionales, alimentan la tensión entre texto y comunidad, proyectándola hacia su interpretación, llamada a concretar su contenido material.

Estas fuerzas políticas tensionan la carta desde la diversidad constitutiva de una comunidad compleja y plural que, a la vez, legitima el ordenamiento constitucional. Su indeterminación es el reflejo de dicha diversidad que, a la vez, la garantiza. Esa permanente tensión política sobre el texto representa la evolución que experimentan los criterios de fundamentalidad del pacto político, que modifican el contenido de las normas constitucionales que positivan dicho pacto 5 . La práctica propia de la diversidad constitutiva de lo polí-

\footnotetext{
1 Cfr. SÁnchez (2000). Para JellineK, este es el principal elemento que caracteriza a la reforma de la mutación constitucional: la intencionalidad y conciencia del cambio producido. Cfr. JELLINEK (1991) p. 7.

2 Principalmente JellineK (2000) pp. 482-484, dado el problema que significaría para la vigencia normativa de la Constitución, su reforma por medio de vías no contempladas expresamente por el ordenamiento jurídico positivo.

3 Hart (2004). En la literatura chilena, cfr. Squella (2001) pp. 333 y ss. y Squella (2007).

4 SMEND (1985) p. 46.

5 En el mismo sentido, HäBerle ha señalado que "comprender la Constitución como cultura puede también aclarar mejor el cambio del sentido de las normas constitucionales sin una modificación en su redacción”, HäBERLE (2002) p. 195.
} 
tico $^{6}$ actualiza el contenido material de las normas constitucionales de principio, que luego será recogido por la interpretación institucional de la Carta ${ }^{7}$.

La Constitución es una clara manifestación de dicha tensión: una decisión soberana estructurada desde declaraciones normativas indeterminadas y entregadas, con mayor o menor grado de discreción, a la interpretación como acto de actualización/creación del Derecho. La combinación entre indeterminación normativa y discrecionalidad interpretativa permite comprender el fenómeno de la mutación constitucional, propio del carácter bifronte de la Constitución: pacto político y norma jurídica.

En esta dimensión, el fenómeno constitucional debe considerar las relaciones materiales de poder, en virtud de las cuales es posible distinguir la Constitución no normada (identificada con la normalidad constitucional) y la Constitución normada, compuesta por normas y principios. Los elementos dinámico (normalidad) y estático (normatividad) de la Constitución se interrelacionan constantemente, por lo que el estudio de la norma constitucional debe considerar la forma en que el cambio ininterrumpido de la realidad social transforma el sentido del texto constitucional. Por ello, es posible afirmar que "el Estado es una forma organizada de vida cuya Constitución se caracteriza no solo por la conducta normada y jurídicamente organizada de sus miembros, sino además por la conducta no normada, aunque sí normalizada, de los mismos"8.

Normalidad y normatividad confluyen en aquellos principios positivados pero que carecen de un contenido determinado por cuanto abren el texto de la Carta, ejerciendo una función transformadora que lo incorpora en los cambios que se producen en la normalidad constitucional. Así, la interacción entre normalidad y normatividad viene a relativizar la separación entre ser y deber ser, donde la fuerza normalizadora de la sociedad (ser) se incorpora activamente en la normatividad de la Constitución (deber ser), formando un todo en el que ambos factores se complementan recíprocamente. Se trata de la doble dimensión de la Constitución, que incorpora en su seno el resultado de un estadio cultural entendido como pacto político, a través de una declaración positiva con vigencia normativa, ya que "el contenido y modo de validez de una norma no se determina nunca solamente por su letra [...] sino además por las cualidades de aquellos a quienes la norma se dirige y la observan"9.

La constitucionalización de principios no supone petrificar su contenido, el que necesariamente va a evolucionar con la sociedad, ya sea por la forma en que esta lo vive, o por cómo el principio vive en ella. Cuando una comunidad se otorga un ordenamiento fundamental, lo hace desde los principios que reconoce como válidos en determinado momento histórico; pero así como su contexto cultural la condiciona al punto de no poder prescindir de ellos, su contenido se relativiza frente a ese mismo contexto del cual emergen, sin que su reconocimiento normativo signifique la petrificación de su contenido. La protección constitucional de la igualdad ante la ley es un buen ejemplo: este "precepto recibe únicamente

6 Mouffe (2003).

7 Recordemos que SMEND escribe desde un ordenamiento constitucional sin Tribunal Constitucional, que podría eventualmente canalizar los cambios constitucionales a través de la interpretación, integrando la vida en el Estado de cara al cambio de circunstancias; BöCKENFÖRDE (2000) pp. 184-185 y 194-196.

8 Mouffe (2003) p. 37.

9 Heller (2004) p. 292. 
su contenido de las concepciones que dominan en la realidad social, y que en la Constitución misma no se formulan o solo se formulan en muy pequeña parte, sobre lo que debe estimarse igual o desigual"10. Así, la misma declaración normativa del principio ha incorporado progresivamente las reivindicaciones raciales y de género, a la igualdad política, a la igualdad social. El sistema jurídico ha experimentado cambios significativos mediante la complejización de las normas de principio, por ejemplo, ampliando las categorías sospechosas de discriminación arbitraria sin que sea modificado el enunciado normativo ${ }^{11}$.

La Constitución se encuentra permanentemente abierta a ser actualizada a través de los cambios que experimenta la comunidad que la dota de legitimidad. Idealmente estos cambios han de reflejarse en reformas formales al texto de la Constitución, pero lo cierto es que los procesos democráticos que se desarrollan en el seno de la sociedad tienen ritmos diferentes, lo que puede generar cambios en el contenido material de las normas positivas sin que sea necesario reformar su texto. El artículo $4^{\circ}$ de la Constitución chilena ("Chile es una república democrática”) es un buen ejemplo de ello: el concepto de democracia que se desprende de dicho artículo y del desarrollo normativo realizado por el resto de las normas constitucionales, ha evolucionado significativamente, abandonando la concepción de una democracia orgánica y protegida propia de la primera etapa de vigencia de la Carta ${ }^{12}$. Sin convertirse en una norma vaciada de contenido, el artículo $4^{\circ}$ en cuestión ha transitado notablemente desde la concepción de democracia protegida de la dictadura, hacia una democracia (progresivamente) en forma. Este proceso de democratización ha sido impulsado desde la comunidad hacia la Constitución, lo que ha generado una serie de reformas al texto que derivan de la disconformidad que existe entre la normatividad y la normalidad constitucional, es decir, entre lo que la Constitución 'entendió' originalmente por democracia y lo que la comunidad que se autogobierna a través de la Carta entiende hoy por democracia: "El sentimiento constitucional presente en cada momento vivido pasa a permear la realización de la Constitución, y la naturaleza dinámica de la Constitución, como organismo vivo que es, permite que ella pueda acompañar la evolución de las circunstancias sociales, políticas y económicas"13.

\section{B. SU DIMENSIÓN DEMOCRÁTICA}

La mutación constitucional tiene una dimensión democrática, desde que la indeterminación del texto fundamental permite diversas concreciones según los acuerdos políticos de una sociedad en cada momento histórico. Su dimensión política evidencia que la Constitución no es deslinde y acotamiento de las relaciones políticas propias de una sociedad

\footnotetext{
10 Heller (2004) p. 294.

11 Heller (2004) p. 295: “mediante la evolución gradual de los principios jurídicos puede suceder que, no obstante permanecer inmutable el texto del precepto jurídico, su contenido experimente una completa revolución, aunque queda salvaguardada la continuidad del Derecho ante los miembros de la comunidad jurídica [...] Dado que tradición y revolución suponen solo oposiciones relativas, se hace posible la permanencia y capacidad de acomodación de la normatividad respecto a la normalidad y puede así concebirse a la constitución total del Estado como 'forma acuñada que viviendo se desarrolla"' (destacado en el original).

12 Cf. Palma (2008). Desde perspectivas diferentes, véase también Nogueira (2008) y Carrasco (2008).

13 Sant'Ana (2012) p. 387.
} 
plural y compleja, sino la coordinación de la convivencia política a partir de ciertos supuestos mínimos que la garanticen (como los derechos fundamentales ${ }^{14}$ ).

Dado el actual paradigma de la soberanía popular como fuente de legitimación del poder político y del Estado ${ }^{15}$, es importante preguntarse qué busca una comunidad al dar/ aceptar una Carta. Una norma de rigidez extrema o excesivamente reglamentaria puede condicionar a tal punto la futura autonomía política de la comunidad, que bien puede incorporarse en aquello a lo que un soberano, aunque renuncie, no renuncia. La pretensión de perpetuidad de determinado pacto político solo puede verificarse en la medida que se limite a lo básico, a los mínimos fundamentales de la convivencia democrática. Una pretensión excesiva en este sentido será, tarde o temprano, fuente de ilegitimidad del texto o forzará a la mutación de sus contenidos. Por ello, vemos la indeterminación constitucional como una garantía no solo para la estabilidad de la Carta, sino para la libertad política de la comunidad: "la Constitución debe permanecer incompleta e inacabada por ser la vida que pretende normar vida histórica y, en tanto que tal, sometida a cambios históricos [, ya que] si la Constitución quiere hacer posible la resolución de múltiples situaciones críticas históricamente cambiantes, su contenido habrá de permanecer necesariamente 'abierto al tiempo"'16.

La Constitución no regulará todos los aspectos de la convivencia democrática. Si lo hiciera, no solo sería un texto interminable, sino también opresor. Cada comunidad históricamente determinada tiene el derecho y el deber de autogobernarse; el ordenamiento constitucional no debe petrificar opciones políticas, sino garantizar el juego democrático y su capacidad para concretar su contenido. Lo único que no debe quedar indeterminado son los fundamentos de la comunidad y cómo se resolverán las discrepancias que estos puedan generar; así, la Constitución contiene un núcleo estable de aquello que la comunidad ha decidido y que no está permanentemente sometido a controversia, pero que podría ser revisado a futuro ${ }^{17}$.

Desde esta perspectiva, la mutación constitucional adquiere una dimensión democrática que no se puede desatender. El diseño de 1980 mantiene vigente, aún hoy, algunos elementos que han cerrado la posibilidad de actualización por las fuerzas políticas, entre otros, por el sistema de fuentes formales que contempla la Constitución chilena (artículo 66). Las distintas normas de rango legal que contempla la Carta vigente han escindido al legislador democrático en distintos quórum y en diversas competencias, limitando su facultad de representar fielmente la voluntad de la mayoría en la configuración del ordenamiento jurídico.

\footnotetext{
${ }_{14}$ Bоввіо (2007) p. 26.

15 Marshall (2010) pp. 254 y ss.

${ }^{16} \operatorname{HesSe}(2011)$ p. 46.

17 Esta es la principal tarea pendiente en el proceso de legitimación democrática de la Constitución chilena, y hacia la cual debiera apuntar el desarrollo del Derecho constitucional: permitir primero, y garantizar después, que el contenido mínimo de este núcleo pueda ser determinado democráticamente por la propia comunidad, superando las técnicas de amarre articuladas por la dictadura. Ello supone revisar (mientras no se promulgue una nueva Carta) tanto los procedimientos y las competencias que contempla la Constitución vigente para decidir las cuestiones que se han dejado abiertas, como el contenido de aquel núcleo base, determinado en dictadura y hoy cerrado a la revisión democrática. Solo así, este núcleo tendrá la legitimidad democrática suficiente para dotarlo de la estabilidad que requiere el ordenamiento constitucional, evitando así las sucesivas reformas que ha experimentado la Constitución chilena.
} 
En este sentido, el proceso de democratización de la Constitución, incluso vía mutación constitucional, es una consecuencia que deriva de la propia función que esta cumple en la comunidad, por cuanto garantiza, tanto a través de prescripciones materiales como de normas competenciales y procesales, que su diseño no se transforme en "un sistema cerrado que excluya la alternatividad de los objetivos e inaccesible a la actuación de diferentes fuerzas" 18 . Hoy la Constitución chilena es el resultado de una combinación entre el proyecto de 1980 y las sucesivas reformas, principalmente de 1989 y 2005, con un elemento adicional: sus normas de principio o de contenido, aquellas que explicitan y positivan los fundamentos básicos del ordenamiento constitucional, aquellas normas preliminares al juego democrático, se asientan en un grado de acuerdo político muy distinto a aquel en virtud del cual fueron positivadas. Como consecuencia de ello, el contenido material de dichas normas ha evolucionado, dando paso a la mutación de la Carta.

Esta se encuentra dentro de la propia cualidad de la Constitución, que convive con su rigidez formal ${ }^{19}$. Mientras la apertura de las normas de principio permite responder al cambio histórico y a la diversidad de las situaciones vitales, las reglas aportan la estabilidad normativa que preserva a la vida en comunidad de su disolución en un cambio continuo. Esta posibilidad de respuesta al cambio histórico dentro de la rigidez de la Constitución, se materializa en las posibilidades de determinación del contenido normativo de los enunciados constitucionales.

No es la voluntad del constituyente histórico la que fundamenta la vigencia actual de la Carta; por el contrario, debe su (i)legitimidad al (des)acuerdo que existe en torno a su contenido. El mismo concepto de Constitución, en tanto garantía de libertad, de derechos políticos y de autogobierno, impide anclar su legitimidad y contenido en un momento pretérito. Por el contrario, la apertura de sus normas garantiza que la propia comunidad actualice su pacto constitucional, a través de las diversas concretizaciones que permite el texto. Como los resultados serán, inevitablemente, variables, toda Constitución se encontrará sometida a un estado de mutación constante, más o menos perceptible y de difícil formalización, pero que también forma parte del proceso de legitimación.

\section{Mutación y FUENTES FORMALES}

No obstante lo señalado previamente, es necesario tener presente que el principal problema que enfrenta la evolución en los contenidos materiales de la Constitución es su falta de formalización, a través de su incorporación a las fuentes formales del Derecho, con el fin de evitar que dicha formalización quede al arbitrio del juez constitucional. En este sentido, el reconocimiento debiera concretarse en sede legislativa, con el fin de incorporar esta evolución en el sistema de fuentes del Derecho. Sin embargo, la incorporación de estos cambios al texto positivo también enfrenta desafíos importantes, ya sea por la formalidad y rigidez de la reforma constitucional, o bien por la dificultad de traspasar los cambios en los consensos

\footnotetext{
18 Hesse (2011) p. 47.

19 Hesse (2011) pp. 51-55.
} 
constitucionales al sistema de quórum de la Constitución chilena ${ }^{20}$. Asumiendo una concepción no cognoscitivista de la hermenéutica, la jurisdicción constitucional puede cumplir una función importante en la medida que la Constitución sea interpretada conforme a las necesidades propias de cada momento histórico, sin anclar el sentido de la norma al momento constituyente y cuidándose de no cercenar el ámbito competencial del legislador.

A esta problemática subyace, por tanto, la tensión teórica que enfrenta al originalismo, en tanto escuela de interpretación constitucional, con aquellas que promueven una interpretación más dinámica del texto fundamental; su punto de discordia radica en cuánto debe prevalecer el momento constituyente en la interpretación de la Carta vigente. La actual manifestación de esta corriente, propia de la tradición legal angloamericana, surge como una reacción crítica a la jurisprudencia de la Suprema Corte de Estados Unidos, durante las presidencias Warren y Burger. Concretamente, se le reclamó mayor fidelidad a la intención original de los redactores de la Constitución de dicho país, acusándole de vulnerar la función que debe cumplir en una democracia, al crear derechos por vía interpretativa. Hubo un primer originalismo que se manifestó contrario a sentencias emblemáticas de la Corte (como es el caso de Roe vs. Wade que se pronunció sobre la interrupción voluntaria del embarazo), que en tanto teoría reactiva y crítica a determinada práctica judicial, fue mutando desde la defensa de la original intent hacia un original meaning, más preocupado por fortalecer la fidelidad de los jueces a la Constitución antes que, simplemente, de restringir su actuar ${ }^{21}$. Esta nueva dimensión del originalismo acepta que se trata de una teoría de interpretación y no de adjudicación constitucional, reconociendo el alto grado de indeterminación de una Carta, particularmente en materia de derechos fundamentales ${ }^{22}$.

Este originalismo (particularmente el primero, adoptando la forma del criterio 'historia fidedigna del establecimiento de la norma’ que contempla el art. 19 del Código Civil) ha tenido ciertas manifestaciones en un sector de la doctrina constitucional chilena que, al reconocer en las Actas de la Comisión de Estudios de la Nueva Constitución (CENC) la fuente de historia e interpretación fidedigna de la Carta vigente, se situó en una suerte de originalismo metodológico ${ }^{23}$. Sin embargo, es necesario precisar que ello no contó con el nivel de desarrollo teórico que se aprecia en la tradición angloamericana ${ }^{24}$. Esta opción metodológica de parte de la doctrina obedece a cierta concepción de la Constitución y, en consecuencia, cómo ha de interpretarse: que refleja un único contenido normativo correcto posible, que el intérprete puede alumbrar con ayuda de las Actas. Se asume que el poder constituyente identificado en la CENC definió el contenido de la Norma Fundamental, el

20 Artículos 66 y 127. Asimismo, la jurisprudencia del Tribunal Constitucional ha ampliado sistemáticamente el ámbito de competencia del legislador especial (de quórum calificado u orgánico constitucional); a modo de ejemplo, la STC 1415-09, en cuyo voto razonado la ministra Peña considera que la ratificación del Tribunal Penal Internacional es materia de ley de quórum calificado (Considerando $10^{\circ}$ ).

21 Smith (2011) pp. 711-713. Sobre el contenido del originalismo original, Powell (1985).

22 Balkin (2007); Solum (2011).

23 Como ejemplos del uso y abuso de las Actas como fuente de interpretación constitucional, particularmente en materia de derechos fundamentales, véase Evans (1999); Cea (2012); Verdugo et al. (2002); SiLva (1997-2010).

24 Parcialmente anotado por Verdugo y García (2013) pp. 141 ss. 
que debe no puede ser alterado vía de interpretación constitucional ${ }^{25}$. Sin embargo, si aceptamos que la función de la Constitución es garantizar la apertura del sistema democrático, protegiendo los mínimos necesarios para la convivencia pacífica, una norma fundamental no puede reemplazar la discusión política para asegurar la permanencia de determinado proyecto político; por el contrario, debe garantizar la apertura para la concretización del contenido de los enunciados normativos ${ }^{26}$. En ese contexto teórico, la discusión por el fenómeno de la mutación constitucional cobra protagonismo, en particular cuando se han consolidado escuelas de interpretación constitucional que, antagónicas al originalismo, postulan la necesidad de interpretar la Norma Fundamental recogiendo la evolución que esta puede experimentar en tanto fenómeno cultural ${ }^{27}$.

La mutación surge por la existencia de una nueva situación jurídica que no corresponde al sentido del texto: "no se modifica un determinado artículo de la Constitución, sino un principio de la Constitución resultante del sistema general de normas constitucionales" 28 . En el caso chileno, esto es evidente: la Constitución fue diseñada para regir en dictadura y bajo los ideales que esta tenía de la sociedad civil. El resultado del plebiscito de 1988 y el referéndum de reforma constitucional de 1989 dan paso a una situación distinta a la prevista originalmente. El complejo proceso de reforma constitucional supone también la mutación del resto del texto, en la medida que lo no reformado formalmente 1. ya no obedece a la lógica constitucional del momento originario, al formar parte de un código político diferente, y 2. es legitimado de distinta manera por una sociedad que no prestó su consentimiento en 1980 y que, además, comprende de otra forma las declaraciones constitucionales que positivan principios (principalmente, los capítulos I y III de la Carta).

No se trata de un quiebre en la vigencia normativa de la Constitución, sino de una manifestación de la conexión entre la norma fundamental y la evolución del pueblo en tanto soberano (realidad o normalidad constitucional). Estaríamos en presencia de un elemento propio de una concepción dinámica de la Constitución: la mutación formaría parte de ella dada su fuente de legitimación política, lo que permitiría superar la brecha entre realidad y norma. En definitiva, se trata de explicitar la relación que existe entre la política y el Derecho, particularmente respecto a la legitimación del ordenamiento constitucional, que hunde sus raíces en la soberanía popular.

Este proceso de mutación encuentra un límite infranqueable en el texto vigente, dando paso a su revisión y reforma ${ }^{29}$. Aunque la mutación deriva de las mismas características de la Constitución, puede llegar un momento en la evolución del consenso constitucional en el cual una reforma sea imperiosa y ya no baste una concretización a partir de la interpretación. En efecto, si los cambios en el ámbito normativo significan una modificación en el programa normativo de la Carta, esta requerirá de reforma expresa ${ }^{30}$. Esta es la

\footnotetext{
5 BASSA (2013).

26 Hesse (1011).

27 STrauss (2010); ACKERMAN (2011).

28 SÁNCHEZ (2000) p. 127.

29 Hesse (2011) p. 54.

30 BÖCKENFÖRdE (2000) pp. 194-195.
} 
situación de la Constitución chilena vigente: la radical transformación del ámbito de aplicación de la norma (el tránsito de la dictadura a la democracia) y la progresiva evolución del consenso constitucional, manifestadas a través de una serie de reformas a la Carta, han dado paso a la mutación del texto en tanto conjunto. Así, reforma y mutación forman parte del proceso de democratización de la Constitución, evidenciando el cambio en los contenidos de las normas abiertas, por ejemplo, a través de los criterios de fundamentalidad de los derechos. Ello ha alterado el sentido original de la Constitución, adecuándolo al nuevo escenario de realidad política. De esta forma, y sin perjuicio del momento constituyente que puede estar viviendo Chile en este momento, la mutación del texto ha contribuido en su proceso de democratización, significando el abandono de las concepciones originales propias de un momento histórico y un contexto institucional que nada tienen que ver con el actual; esta mutación se verifica "cuando las prescripciones constitucionales son interpretadas de acuerdo con las cambiantes concepciones y necesidades de la época, sin atenerse al tenor literal de la Constitución o sin tener en cuenta el sentido con el que dotó originalmente el legislador constitucional a las normas en cuestión" ${ }^{31}$.

Una transformación mayor señalaría el camino a una eventual reforma constitucional o, derechamente, la redacción de una nueva, mas no podría justificar una sustitución de la Carta, como fuente formal del Derecho, por una intensa función normativa de la jurisprudencia constitucional, que relativice la vigencia de las disposiciones constitucionales ${ }^{32}$. La función de la interpretación es determinante para la realización del texto, particularmente en aquellos enunciados que positivan principios. La posibilidad de concretizar dichos contenidos a través de una interpretación abierta a los cambiantes consensos constitucionales, podría permitir una plena realización de la Constitución y del autogobierno del pueblo, del cual esta es garantía. Pero no puede erigirse en su reemplazo como decisión soberana del pueblo ni como árbitro del proceso político.

Así, junto a la interpretación constitucional, cobran especial importancia las reglas de atribución de competencias en la materia, la determinación de qué interpretación reconoceremos como válida (si el legislador, el Tribunal Constitucional, la comunidad) y, especialmente, de la función del Tribunal Constitucional: si garantizar la intangibilidad de la decisión constituyente o si, por el contrario, la apertura del proceso democrático. En estas materias, tanto el ordenamiento constitucional como la dogmática constitucional chilena están en deuda, dada la configuración actual del sistema competencial en materia de interpretación y control constitucional ${ }^{33}$, y la forma como la doctrina ha incorporado, en forma histórica, el contenido constitucional del momento constituyente.

31 SÁNCHEZ (2000) pp. 129-130.

32 BÖCKENFÖRDE (2000) pp. 195-196.

33 STC 1288-2008, motivada por el control preventivo de constitucionalidad de la Ley Orgánica Constitucional del Tribunal Constitucional. Especialmente, Considerandos $43^{\circ}$ a $77^{\circ}$, en los que el Tribunal Constitucional defiende su competencia para conocer la inconstitucionalidad de los tratados internacionales por vía incidental (art. 93 No 6), a contrapelo de lo señalado en el proyecto de ley emitido por el Congreso Nacional. 


\section{MUTACIÓN EN LOS CRITERIOS DE PROTECCIÓN CONSTITUCIONAL DE LOS DERECHOS A LA SALUD Y AL TRABAJO}

\section{A. La mutación de los Derechos}

El sistema de protección y respeto de los derechos fundamentales, en gran parte se determina por el tratamiento que la propia Constitución hace de ellos, aunque tanto la protección legal como el propio desarrollo de la cultura jurídica cumplen una función propia. Históricamente, su protección se encuentra condicionada por las categorías tradicionales que clasifican los derechos atendiendo a su generación o desde la distinción entre libertad negativa y positiva. Ello ha derivado en una desprotección relativa de los llamados derechos económicos, sociales y culturales frente a los civiles y políticos, en particular los que protegen la propiedad y la actividad económica; una prueba de ello es su exclusión del amparo contenido en el artículo 20 de la Carta.

La debilidad de los derechos sociales se verifica en el contexto de una Constitución económica y social herencia de una dictadura de cuño ideológico, autoritario y neoliberal, que encabezó una refundación del capitalismo destinada a imponer un modelo de Estado mínimo o subsidiario ${ }^{34}$. Este individualismo radical desde el cual se construyó el sistema vigente de protección de derechos fundamentales en Chile, ha debilitado significativamente la protección de aquellos bienes, intereses y necesidades de la persona situada en un mundo relacional y que se expresan normativamente a modo de derechos sociales.

Ello se verifica en la propia concepción política que la Comisión redactora del texto original de la Carta vigente tuvo de estos derechos: el sistema se construyó desde su consideración como meras expectativas con valor simplemente programático; dado que su satisfacción dependería de la capacidad económica del Estado, no cuentan con garantía jurisdiccional directa. En efecto, el comisionado Guzmán prefirió "reservar el concepto de derecho a aquellas facultades para cuyo ejercicio por su titular solo se requiere que un tercero no se lo impida (...) Distinto es el caso de las pretensiones o aspiraciones sociales, cuya denominación como 'derecho' (a la salud, vivienda, educación) resulta más bien equívoca, porque sus posibilidades de vigencia dependen de la capacidad económica de cada sociedad y mal podría, por ende, pretender recabarse de un tribunal de justicia. Pienso que llamar derecho a los que son aspiraciones -muy legítimas, notables y justas-, pero que no siempre se pueden satisfacer aunque haya la mejor voluntad de realizarlo, presenta el riesgo de que todo Estado y gobierno sea acusado por ello de no respetar los derechos humanos, privando entonces al juicio de todo valor efectivo o práctico" 35 .

De esta forma, la Constitución vigente fue configurada desde el ideal del Estado liberal-decimonónico, por lo que su accionar está condicionado por el principio de subsidiaridad y la garantía de la abstención estatal frente al ejercicio de los derechos fundamentales; es decir, desde la separación sistémica entre Estado y sociedad, donde aquel debe garantizar los espacios de autonomía individual. Desde este modelo, la protección de los derechos sociales se ve seriamente disminuida.

\footnotetext{
34 ZÚNiga (2008) p. 2.

35 Rojas (1996) p. 148.
} 
Ninguna de las múltiples reformas constitucionales ha modificado significativamente el sistema de protección de derechos fundamentales. No obstante lo anterior, la doctrina más reciente ha roto las cadenas de la interpretación originalista a través de un modelo teleológico, evidenciando cierta mutación en el contenido que se le atribuyó a la Carta durante las primeras décadas de su vigencia ${ }^{36}$. Su trabajo ha generado cierto impacto en la jurisprudencia constitucional, que ya muestra una incipiente tendencia hacia el abandono progresivo del originalismo en la interpretación del texto vigente, según veremos a continuación.

\section{B. Antiguos criterios para la configuración de los Derechos a la SALUd y al TRABAJO}

La mutación constitucional, como se vio, es un fenómeno que afecta el contenido del enunciado normativo, pero sin mediar una reforma explícita al texto. Para comprobar si este se ha verificado respecto de los derechos sociales (en concreto, salud y trabajo), es fundamental fijar el punto de inicio de este proceso, es decir, cuáles son los criterios que originalmente configuraron el contenido constitucional de estos derechos, para luego identificar los nuevos elementos de configuración. El análisis de la jurisprudencia constitucional ha arrojado interesantes resultados, siendo posible identificar los antedichos criterios tanto en jurisprudencia de sede constitucional como ordinaria. Sin perjuicio que será posible establecer ciertos matices en lo sucesivo, hay una cultura jurídica de larga data que se aprecia en la jurisprudencia ordinaria, aun antes de la promulgación de la Carta vigente, y que se proyecta hacia las primeras décadas de la jurisprudencia del Tribunal Constitucional ${ }^{37}$.

La configuración de la protección del ejercicio de los derechos en estudio, a partir de la determinación de su contenido por el Tribunal Constitucional, ha recogido una estructura que ya se encontraba presente en la jurisprudencia constitucional ordinaria. Aquí radica el punto de inicio del proceso de mutación constitucional propuesto por la presente investigación, razón por la cual nos detendremos para identificar los principales criterios de configuración jurisdiccional de los derechos a la salud y al trabajo, tanto en sede ordinaria como en sede constitucional.

\section{Propietarización de los derechos}

La teoría de la propietarización de los derechos postula que dado que se adquieren bajo la vigencia de una determinada normativa, ingresan al patrimonio de sus titulares, quienes ejercerían un derecho de dominio sobre ellos, protegido por el derecho de propiedad del artículo $19 \mathrm{~N}^{\circ} 24$ de la Constitución, que garantiza la propiedad sobre los bienes incorporales. A su turno, el artículo 583 del Código Civil señala que "sobre las cosas incorporales hay también una especie de propiedad", incorporando un argumento normativo que permite respaldar la idea de propiedad sobre derechos y créditos. Ha sido esta la forma de justificar la existencia de una propiedad sobre los derechos, incluso los fundamentales, consagrándose la teoría de su propietarización. De esta forma, si bien el derecho de propiedad tiene por objeto proteger la integridad patrimonial de las personas, la jurisprudencia

36 Aldunate (2008); Atria (2007); Contesse (2002); Ruiz-Tagle (2001); Zúñiga (2008).

37 BASSA (2013). 
de la década del 70 muestra una extensión de su contenido, al entender que existe plena propiedad sobre los bienes incorporales, sin distinguir entre derechos patrimoniales y fundamentales, aplicando a estos la doctrina de la propietarización ${ }^{38}$.

La historia constitucional chilena reciente, muestra un fortalecimiento del derecho de propiedad, quizá destinado a defender a los propietarios antes que a la institución jurídica. Tal como ocurrió en el sistema jurídico alemán de la década de 1920, en Chile se dio protección a un conjunto de derechos e intereses patrimoniales que no se correspondían con el concepto tradicional de propiedad, proceso que se consolidó en la jurisprudencia de la Corte Suprema de Justicia a fines de la década de 1970. Esta propietarización de los derechos se consolidó, luego, en la jurisprudencia del Tribunal Constitucional de la década de $1990^{39}$. Como consecuencia de la consolidación de este fenómeno, la Corte Suprema ha recurrido a la garantía de la propiedad para proteger el derecho a la salud, afirmando que "en la negativa arbitraria de una Isapre a otorgar la cobertura pactada en el contrato no vulnera la garantía constitucional del $\mathrm{N}^{\circ} 9$ del artículo 19, pero sí el ejercicio del Derecho de Propiedad del $\mathrm{N}^{\circ}$ 24 de dicho artículo de la Constitución, dado que se priva a aquella de la legítima percepción de un beneficio pecuniario que ha debido incorporarse a su patrimonio" ${ }^{40}$.

Lo propio ha sucedido en materia de derecho al trabajo, donde es posible identificar jurisprudencia que lo ha protegido indirectamente, mediante la protección de la propiedad. De esta manera, la Corte de Apelaciones de Santiago señaló que "el derecho del trabajador a gozar de un empleo estable mientras cumpla debidamente con sus obligaciones funcionarias, constituye una especie de propiedad sobre un bien incorporal, garantizado por el $N^{\circ} 24$ del artículo 19 de la Constitución, de modo tal que el trabajador solo puede ser privado de su empleo por los medios que la propia ley establece" ${ }^{\text {41. }}$.

En ambos casos, se puede apreciar que el objeto de la protección, a juicio de las Cortes, es la propiedad que existe sobre el derecho fundamental, o bien sobre las facultades que otorga ese derecho. A nuestro juicio, esta técnica de protección indirecta desvirtuó el sistema de protección de los derechos fundamentales, empobreciendo su contenido. La protección de los derechos requiere de un adecuado desarrollo dogmático de su contenido constitucional; mediatizar su protección por medio de un derecho más fuerte termina por desnaturalizar ambas instituciones. En especial si el régimen de protección responde a categorías ius privatistas, ajenas al sistema de protección ius fundamental.

Lo propio ha sucedido en el Tribunal Constitucional, quien al pronunciarse sobre la protección del derecho al trabajo, señaló explícitamente que "de acuerdo con lo dispuesto en el artículo $19 \mathrm{~N}^{\circ} 24$ inciso primero de la Constitución Política, esta reconoce a toda persona, el derecho de propiedad en sus diversas especies sobre toda clase de bienes corporales e incorporales, por lo cual sobre derechos emanados de un contrato de trabajo que son bienes incorporales y entre los cuales está el derecho de percibir una remuneración pactada,

\footnotetext{
38 Vergara (1991-92) p. 284; Sacco (2006) p. 480.

39 Cordero (2006) p. 129.

40 Corte Suprema, “Rodrigo Alamos con Isapre Colmena Golden Cross S.A.”, Rol No 14.167-1988, Considerando $8^{\circ}$.

41 Corte de Apelaciones de Santiago, Rol N 14.347-1988, Considerando 5º
} 
sus titulares tienen propiedad" ${ }^{42}$. Siguiendo las doctrinas civilistas más clásicas, él entendió que de un contrato de trabajo surgen derechos que se incorporan al patrimonio de los contratantes y, por tanto, obtienen protección constitucional vía derecho de propiedad.

De esta forma, es posible identificar una primera etapa jurisprudencial, que configuró los derechos a partir de categorías de derecho privado, vinculadas a la contratación entre particulares. El principal elemento fue la ampliación del derecho de propiedad para proteger, secundariamente, el ejercicio de otros derechos. Así, durante largos años, para obtener protección judicial de cualquier derecho subjetivo, debieron recurrirse a este expediente de considerar protegible no tanto el "derecho", sino la propiedad que este tendría. Se generó un proceso de propietarización de los derechos fundamentales, que impidió fortalecer un sistema de protección dirigido, directamente, sobre los derechos en tanto instituciones con ámbitos propios ${ }^{43}$. A mayor abundamiento, propietarizar la protección constitucional de los derechos contribuyó a genera una jerarquía al interior del catálogo, por cuanto el derecho de propiedad adquirió dimensiones de supraderecho, a través del cual se otorga tutela a otros que son percibidos con un inferior desarrollo dogmático. Esta consecuencia también se ha convertido en un criterio jurisdiccional para la protección de los derechos fundamentales, como veremos a continuación.

\section{Jerarquía entre derechos}

Existe una tendencia en la doctrina chilena tradicional hacia jerarquizar los derechos reconocidos por la Constitución ${ }^{44}$, incluso al grado de desconocer la condición de fundamentales de los derechos sociales ${ }^{45}$. Si bien no se trata de una postura mayoritaria en el constitucionalismo contemporáneo y que ha sido objeto de revisiones sustantivas ${ }^{46}$, ha influido en la jurisprudencia nacional. Esto se debe a una serie de factores, entre los cuales destacan las opciones políticas juridificadas en 1980, la interpretación originalista y la ausencia de criterios de interpretación propios de los derechos fundamentales. En este sentido, las afirmaciones de Jaime Guzmán en la CENC, que define los derechos a partir de una concepción muy limitada, han sido muy influyentes; señaló que "son aquellas facultades para cuyo ejercicio, por su titular, solo requiere que un tercero, sea la autoridad o un particular, no se lo impida o coarte ilegal o arbitrariamente ${ }^{47}$. Lo anterior permitiría explicar por qué se ha recurrido a la idea de jerarquía para solucionar conflictos entre derechos, que los

42 STC No 698 , Considerando $\mathrm{N}^{\circ}$ 9, letra f.

43 Vergara (1991-92) p. 291.

${ }^{44}$ Por todos, cf. CEA (2012) p. 66: "tiene que admitirse la idea de jerarquía o gradación, de primacía o preponderancia de unos sobre otros de esos derechos [...] En ese sentido, creemos que en la enumeración del artículo 19 [de la Constitución] no están los derechos al azar, sino que ordenados siguiendo la secuencia jerárquica enunciada. Y lo mismo cabe asegurar del orden con que aparecen asegurados en los Pactos Internacionales respectivos".

45 Cfr. Martínez, "Los derechos sociales", p. 447 y (2008), pp. 282-283; GÓmez (1993), p. 84: "Si los derechos humanos o esenciales se extienden sin límite a los de primera, segunda y tercera generación y así sucesivamente, la teoría del mercado como asignador de los recursos y la teoría de las decisiones públicas pierden sentido”.

46 A este respecto se ha mostrado un avance importante en Aldunate (2008), y reseña en BaSSA (2010).

47 Rojas Sánchez, Gonzalo, Derecho Politico. Apuntes de las clases del profesor Jaime Guzmán Errázuriz, Santiago, Ediciones Universidad Católica de Chile, p. 36. 
criterios clásicos de interpretación no resuelven satisfactoriamente ${ }^{48}$. Es una manifestación de la tradicional preferencia otorgada a los derechos de libertad por sobre los derechos positivos (a pesar del sólido cuestionamiento que se ha realizado a esta clasificación ${ }^{49}$ ).

Un ejemplo ya tradicional de esta tendencia se encuentra en un fallo de la Corte de Apelaciones de Santiago de 1993. Al resolver un conflicto entre los derechos a la libertad de expresión y a la honra, afirmó que "nadie discute que el constituyente siguió, aunque nadie lo da expresamente, un orden de prelación en las garantías y derechos que consagra el artículo 19 (de la Constitución). Desde luego, la ordenación en que aborda tales derechos y garantías no es arbitraria, como lo prueba la sucesión descendente de su importancia. Así se comienza con la vida e integridad persona, luego la igualdad ante la ley, después la igual protección ante la ley, en seguida, en el número 4, la honra, en circunstancias que la libertad personal está consagrada en el número $12 " 50$.

En idéntico sentido se pronunció la misma Corte de Apelaciones, el año 1996, al conocer de un recurso de protección presentado por varios particulares por sí y a nombre de Jesucristo y de la Iglesia Católica, por la revisión que efectuó el Consejo de Calificación Cinematográfica, de su resolución de 29 de noviembre de 1988, por el cual quedaron prohibidos en Chile la internación y exhibición de la película "La última tentación de Cristo", dirigida por Martin Scorsece. Dicho fallo acoge el recurso de protección, decisión que fue ratificada por la Corte Suprema de Justicia, protegiendo la honra de Jesucristo porque "esta prevalece con respecto a la libertad de emitir opinión o de informar" 51.

Parte de la jurisprudencia de la década de los 90 se vio influenciada por una temprana doctrina constitucional que entendió que los derechos del artículo 19 de la Carta no se encontrarían enumerados al azar, sino que enumerados en relación a un orden de jerarquía de los mismos $^{52}$. Como consecuencia de esta creencia, se garantizó el ejercicio de los derechos a partir de criterios apriorísticos que no contribuyeron a su adecuado desarrollo dogmático. Cabe señalar que la jerarquía de los derechos representa una verdad que pretende ser autoevidente. Sin embargo, con independencia de los argumentos que fundamenten el recurso a tal jerarquización para solucionar un conflicto de derechos, es necesario señalar que esta técnica se contrapone con el constitucionalismo contemporáneo, que entiende que los derechos fundamentales conforman un sistema unitario, cuya finalidad es la protección de la persona. Su recepción como criterio de interpretación constitucional ha entorpecido el entendimiento de los derechos fundamentales como manifestación de un proceso progresivo y constante de reconocimiento y protección de los intereses y necesidades de las personas ${ }^{53}$.

\footnotetext{
48 Cfr. BASSa (2013) p. 37.

49 Cfr. Holmes y Sunstein (2011) pp. 55 y ss.

50 Corte de Apelaciones de Santiago, Rol N 983-93.

51 Considerando $N^{\circ} 14$, Corte de Apelaciones de Santiago, Rol No 4079-96. Sentencia confirmada por la Corte Suprema de Justicia, causa Rol N ${ }^{\circ}$ 519-1997.

52 Cfr. Cea (2012), tomo II, pp. 65-68 y Verdugo et al. (2002), tomo I, pp. 197 y 267: se ha afirmado que la Comisión de Estudios para la Nueva Constitución (1973-78) habría organizado los derechos fundamentales jerárquicamente, atendiendo a los valores que protegen: vida, igualdades y libertades. Para una relación de la situación de aquella dogmática chilena, véase CONTESSE (2002).

53 Aldunate (2008) pp. 273-276.
} 


\section{Libertad contractual}

Uno de los criterios de configuración de los derechos sociales en la jurisprudencia constitucional más temprana, dice relación con la incorporación de la libertad contractual como principio rector del ordenamiento ius fundamental, que se desprendería del propio tenor literal de los numerales 9 y 16 del art. 19 de la Carta. Así lo demuestra, por ejemplo, un fallo de la Corte de Santiago, al señalar que "se infiere que la garantía consagrada en el artículo $19 \mathrm{~N}^{\circ} 16$ de la Constitución, dice relación con dos aspectos de la libertad de trabajo, a saber, la posibilidad y opción de toda persona a contratar libremente sus servicios y la de elegir el trabajo que desea y pretende desempeñar" ${ }^{54}$. Como se aprecia, la Corte no tutela el trabajo en sí mismo, sino que limita la garantía del artículo $19 \mathrm{~N}^{\circ} 16$ a la libertad de contratación del trabajador, en especial a la libertad para elegir el trabajo que desee, dando inicio a una tendencia jurisprudencial recién comenzada la vigencia normativa de la Carta.

En sentido similar se ha pronunciado la Corte Suprema, al afirmar tajantemente que "el N 16 del artículo 19 de la Constitución, no comprende la justa remuneración ni el derecho a la negociación colectiva" ${ }^{55}$, restringiendo el alcance de la garantía constitucional vía interpretación. Para la jurisprudencia constitucional más temprana en la garantía y protección de los derechos fundamentales, aquella que marca el inicio del proceso de mutación que motiva la presente investigación, "el $N^{\circ} 16$ del artículo 19 de la Constitución, en ninguno de sus incisos protege el empleo en sí mismo, o la función o el cargo servido" "56, criterio que será modificado sustantivamente en la más reciente jurisprudencia del Tribunal Constitucional.

Sin embargo, antes de verificarse dicha mutación, el propio Tribunal Constitucional recogió este criterio. Así, la libertad del trabajo fue el principal componente del derecho en cuestión, aunque ahora complementado con el derecho a recibir una justa retribución, entre otros. Lo anterior queda de manifiesto en una sentencia de inaplicabilidad, en procedimiento incoado contra la exclusión de la nómina nacional de síndicos; en la oportunidad, señaló que "la libertad de trabajo, consagrada en el artículo $19 \mathrm{~N}^{\circ} 16$ envuelve, por una parte la tutela de la libertad de trabajo y su protección (...) Toda persona tiene derecho a la libre contratación y a la libre elección del trabajo con una justa retribución" ${ }^{57}$. Recurriendo a la doctrina tradicional ${ }^{58}$, el Tribunal argumenta que la garantía faculta a toda persona a buscar cualquier trabajo que no esté prohibido por ley, señalando además, que en lo relativo a las condiciones en las que se debe ejecutar un trabajo, se garantiza la autonomía del trabajador. Continúa señalando que "este derecho forma parte de la denominada Constitución Económica y debe, por tanto, concordarse con el conjunto de principios que emergen con la Constitución de 1980, especialmente las garantías del artículo 19, que conforman el llamado orden público económico"59.

54 Corte de Apelaciones de Santiago, Considerando 12 y 13, en: Revista de Derecho y Jurisprudencia, LXXIX, 11 de diciembre de 1981, p. 69.

55 Corte Suprema, en: Revista Gaceta Jurídica, No 35 (1983), p. 46.

56 Corte de Apelaciones de Santiago, "Adriana Almazabar con Vicepresidente ejecutivo de la Caja Nacional de empleados públicos y periodistas”, Rol N 162-86.

57 STC No 1413-09, Considerando $\mathrm{N}^{\circ} 21$.

58 Irureta (2006) pp. 49 y 60-63.

59 Apoyándose para esto en, Fermandois Vohringer, Arturo y García García, José, op cit. p. 355. 
Así las cosas, reitera la idea de que de la garantía contenida en el artículo $19 \mathrm{~N}^{\circ} 16$, se desprende el principio de libertad individual, cuestión que habilitaría a toda persona a buscar u obtener un trabajo, asegurando en esto, la no discriminación arbitraria, además del derecho a la justa retribución ${ }^{60}$. Las sentencias referidas dan cuenta de cómo el Tribunal ha configurado el derecho al trabajo, principalmente, desde categorías privadas vinculadas a la contratación entre particulares. Se trata de una interpretación restrictiva del contenido normativo de la garantía constitucional, limitada a su dimensión de libertad, que será modificada en jurisprudencia posterior del propio Tribunal.

Por su parte, el contenido del derecho a la protección de la salud ha sido concretizado siguiendo este mismo criterio de interpretación, desde la libertad contractual. Fallando una apelación contra sentencia de protección de la Corte de Santiago, la Corte Suprema concluyó que "no existe ilegalidad en el proceder de los recurridos, puesto que existe una ley que arregla con precisión el otorgamiento de las prestaciones médicas requeridas"61. En este caso, las prestaciones médicas o de salud no reciben protección constitucional, pues el reenvío al legislador excluiría estas materias de dicha protección ius fundamental, cuyo objeto no es el otorgamiento de tales prestaciones, sino la libertad para acogerse al sistema público o privado de salud.

Los fallos citados dan cuenta de cómo la jurisprudencia constitucional privilegió, inicialmente, la protección de la dimensión de libertad de los derechos fundamentales, incluso de aquellos de carácter social, determinando su contenido normativo a través de criterios de interpretación propios del Derecho Privado, o bien, estableciendo relaciones de jerarquías apriorísticas entre ellos.

\section{Nuevos Elementos CONFIGURAdORES de los DERECHOS SOCIALES PRESENTES EN LA JURISPRUDENCIA CONSTITUCIONAL RELATIVA A SALUD Y TRABAJO \\ Es posible afirmar que la jurisprudencia constitucional chilena ha comenzado a dar} un vuelco ante la protección de los llamados derechos sociales, especialmente respecto de los derechos a la salud y al trabajo. Sentencias recientes han entendido que se estructuran desde una necesidad de garantía jurisdiccional que deriva directamente de su reconocimiento normativo. Para justificar aquello, el Tribunal ha revalorizado conceptos tales como la dignidad de la persona, relativizando la protección de derechos fundamentales desde la aplicación de principios que parecían absolutos, como la subsidiaridad y hasta la propia autonomía de la voluntad.

El hito que quizá marca un quiebre en la materia es la STC 1710, que viene a consolidar la línea jurisprudencial abierta por la STC 976, respecto a la protección del derecho a la salud y las prestaciones contratadas a través de las Instituciones de Salud Previsional (Isapres). Luego de sucesivas declaraciones de inaplicabilidad (SSTC 976, 1218, 1273, 1287),

\footnotetext{
60 En el mismo sentido se pronuncia la STC 1254-08, Considerando $N^{\circ} 89$, señalando que “...la doctrina ha precisado que la libertad de trabajo y su protección, es un derecho constitucional que habilitad a toda persona a buscar, obtener, practicar, ejercer o desempeñar cualquier actividad remunerativa, profesión u oficio lícito, vale decir, no prohibidos por la ley...”, en Evans de la Cuadra, Enrique, Derechos Constitucionales, Tomo III, p. 10. ${ }^{61}$ Corte Suprema, Rol N 3599-2001, Considerando $2^{\circ}$ a $5^{\circ}$.
} 
el artículo 38 ter de la Ley No 18.933 fue declarado inconstitucional, por cuanto el régimen para la determinación del precio de los seguros de salud vulneraba, a juicio del TC, el derecho a la igualdad ante la ley, a la protección de la salud y a la seguridad social ${ }^{62}$. Este cambio en la protección del derecho a la salud, tiene un correlato en la configuración jurisprudencia de otro derecho social, el derecho al trabajo (SSTC 1852, 2086, 2110, 2114, 2182, 2197); sin embargo, es necesario señalar que esta jurisprudencia aún no se encuentra plenamente consolidada, toda vez que existen fallos contradictorios, como lo son las SSTC 2199, 2213, 2186, 2340, 239863 (aunque la sentencia más reciente en la materia, STC 2470, acoge la inaplicabilidad y retoma la línea argumental de la STC 1852). Sin perjuicio de lo anterior, y según veremos, el análisis conjunto de ambos grupos de sentencias permite concluir que el Tribunal Constitucional ha modificado los criterios de interpretación tanto del derecho a la salud como del derecho al trabajo, mutando desde concepciones tradicionales, alejándose del recurso a las actas de la Comisión Ortúzar y, en definitiva, ampliando el ámbito de protección constitucional de estos derechos.

\section{Derechos fundamentales como un sistema unitario}

El sistema de protección de derechos fundamentales es una construcción normativa compleja, compuesta tanto de enunciados normativos de principios como de garantías procesales e institucionales destinadas a proteger su legítimo ejercicio. Esta complejidad ha sido abordada desde diferentes perspectivas, que se han servido de herramientas pedagógicas para establecer diferencias al interior del catálogo que, incluso, han dado paso a la negación del carácter de fundamental de ciertos derechos. Quizá la más importante, por sus efectos, sea la clasificación a partir del binomio libertad positiva/negativa, que da paso a la configuración hermenéutica de derechos negativos (que establecen un deber de abstención) y positivos (que establecen deberes de prestación). Se ha hecho ya un lugar común recurrir a esta clasificación para negar el carácter de derecho a los llamados derechos positivos ${ }^{64}$.

Sin embargo, lo cierto es que todos los derechos requieren de una intervención activa por parte del Estado; la diferencia entre ellos se verifica, a fin de cuentas, en el grado de intervención estatal necesaria para la protección de su legítimo ejercicio. Es decir, hay derechos preferentemente prestacionales y otros preferentemente de abstención, pero ambas 'categorías' de derechos comparten una dimensión común, por cuanto se trata de intereses protegidos constitucionalmente que requieren, sin excepción, de algún tipo de intervención estatal para garantizar su libre y legítimo ejercicio ${ }^{65}$.

Todos los derechos imponen obligaciones positivas al Estado, que deben ser cumplidas en orden a asegurar su ejercicio; desde el establecimiento de un sistema registral destinado

${ }_{62}$ Contreras et al. (2010) p. 655, Zùniga (2011) p. 59, NaSH (2011) p. 109.

${ }_{63}$ Estos grupos de fallos dan cuenta del estado de debate que presenta la controversia al interior del Tribunal Constitucional, donde el criterio para la garantía del derecho oscila entre la protección de las condiciones materiales del trabajo y la protección de la libertad contractual y la justa remuneración del trabajo. Es un momento interesante para el análisis jurisprudencial del fenómeno, pues creemos estar en presencia de una mutación constitucional en marcha, aunque no plenamente consolidada.

${ }^{64}$ Martínez (2010) p. 133, Sánchez y Pereira (1992) p. 262.

${ }^{65}$ Holmes y Sunstein (2011) pp. 63-65. 
a proteger la propiedad raíz, sobre vehículos motorizados, las concesiones mineras o los derechos de agua, hasta la obligación de mantener un sistema de policía y un aparato judicial (razonablemente) eficiente y libre de corrupción. Se trata de prestaciones que el Estado debe proveer para asegurar el ejercicio de todo derecho. Incluso los llamados derechos de abstención, hijos de la primera época posterior al Antiguo Régimen, tienen como correlato un deber de prestación: "ningún derecho es simplemente el derecho a que los funcionarios públicos no lo molesten a uno. Todos son reclamos de una respuesta gubernamental afirmativa" ${ }^{66}$.

La relación de los derechos, además, viene dada porque ambas categorías generan obligaciones positivas y negativas para el Estado y los particulares. Así, por ejemplo, el derecho a la vida incluye algún ámbito de protección del derecho a la salud que significa, a lo menos, asegurar prestaciones mínimas de las cuales depende directamente la vida de las personas; esfera de protección absoluta, que no admite pretextos de orden patrimonial ${ }^{67}$. Por tanto, el Estado no solo tiene una obligación de no hacer, también tiene una obligación positiva. Dicho derecho se ejerce en la medida en que exista la posibilidad de poder gozar de otros, cuyo ejercicio resulta fundamental para su cumplimiento y satisfacción. En ese sentido, una interpretación restrictiva del derecho a la vida supondría desproteger su legítimo ejercicio, por cuanto también se requieren medidas positivas por parte del Estado.

Los derechos económicos, sociales y culturales, por su parte, implican no solo prestaciones positivas estatales, sino también la ausencia de interferencia arbitraria de terceros. Estos constituyen presupuestos y complementos indivisibles para el goce de los derechos individuales, al garantizar determinadas condiciones materiales mínimas, que posibilitan el efectivo ejercicio de tales libertades, sin que sea posible establecer diferencias cualitativas u ontológicas que permitan diferenciarlos de los derechos individuales ${ }^{68}$. Por el contrario, la jurisprudencia del Tribunal Constitucional ha sostenido que los derechos forman un conjunto unitario que goza de plena vigencia normativa; en consecuencia, excluye toda posibilidad de dar una interpretación al catálogo que anule o prive de eficacia a algún precepto, obligación que incluso irradia a los particulares. Se trata de "un sistema orgánico y coherente de valores, principios y normas, todos los cuales guardan entre sí correspondencia y armonía, excluyendo cualquiera interpretación que anule o prive de eficacia a algún precepto de ella" ${ }^{69}$. El Tribunal no deja espacio para construir una interpretación alternativa que legitime una suerte de jerarquización entre derechos, por ejemplo, a partir de los mecanismos jurisdiccionales de protección o de su carácter preferentemente prestacional.

\section{Derechos sociales no son meras expectativas}

Durante décadas, la teoría constitucional clásica se hizo eco de las primeras críticas al Estado Social, al sostener que se trataba de meras expectativas cuya satisfacción depende de la capacidad económica del Estado; recurriendo a la interpretación originalista, se sostuvo que la Carta vigente no los reconocía como derechos. Esta posición se encuentra expresada

\footnotetext{
66 Holmes y Sunstein (2011) p. 64.

67 Zúñiga Fajuri (2011) p. 5.

${ }^{68}$ Nogueira (2009) p. 12.

69 STC 976, C. 34º, Peña Wasaff con Isapre ING Salud S.A. (2007).
} 
tanto en las Actas de la Comisión Ortúzar (sesión 139, entre otras) como en su documento final: "como todo derecho social, el derecho a la educación implica una aspiración del individuo que la comunidad y, particularmente, el Estado tienen el deber de satisfacer en la medida que las posibilidades lo permitan"70. Guzmán, principal expositor de esta postura en los albores de la Carta vigente, lo señala explícitamente: "sus posibilidades de vigencia dependen de la capacidad económica de cada sociedad y mal podría pretender recabarse de un tribunal de justicia” (Rojas, 1996, p. 148). En sentido similar se han manifestado autores como Martínez Estay ${ }^{71}$, incluso negando su condición de derechos en sentido estricto ${ }^{72}$, derivado de su supuesta falta de justiciabilidad ${ }^{73}$.

Sin embargo, es posible apreciar un giro en el contenido de las sentencias del Tribunal Constitucional en la materia, separándose de la interpretación tradicional. La STC 976 es particularmente clara al reafirmar que el derecho a la salud es un derecho fundamental en regla, como lo expresa en los considerandos $26^{\circ}$ ("desde un punto estructural, los derechos sociales no son derechos de una naturaleza necesariamente distinta a los derechos civiles o políticos") y $27^{\circ}$ ("resulta ineludible desvanecer la tesis contraria a que los derechos sociales sean realmente tales, aseverando que poner en duda su 'practicabilidad' de realización, es una idea confusa, porque esa 'reserva de lo posible' lleva a sostener que la Constitución ha de ser 'desactivada', a causa de la imposibilidad económica del Estado de darles satisfacción, convirtiendo así en virtuales las cláusulas fundamentales que aseguran su materialización”), argumentos reproducidos en la STC 1248 (C. $20^{\circ}$ y $21^{\circ}$ ) y confirmados en la sentencia de inconstitucionalidad 1710 (C. $94^{\circ}$ y $\left.95^{\circ}\right)^{74}$. Se trata de una transformación realmente significativa, que da cuenta de la evolución que ha experimentado la cultura jurídica chilena en la protección de estos derechos fundamentales de carácter social. Este ya ha sido recogido por la doctrina, que avizora un cambio en el eje referenciador de protección del derecho a la salud, enfatizando en la dimensión objetiva de las normas de derechos fundamentales y su efecto irradiación sobre el ordenamiento jurídico y los actos privados, como los contratos de salud ${ }^{75}$.

En el mismo sentido, ahora respecto de la jornada laboral del transporte rural colectivo, el Tribunal amplió considerablemente el contenido constitucional del art. $19 \mathrm{~N}^{\circ} 16$, confirmando una mutación desde la protección de la libertad de trabajo ${ }^{76}$ hacia la protección del trabajo en sí mismo "en atención al compromiso inseparable de respeto a la digni-

${ }^{70}$ Comisión de Estudios para la Nueva Constitución (1981) p. 190

71 Martínez (2006) p. 305 y Martínez (1997) p. 134.

72 MarTínez (2008) pp. 282-283.

73 Martínez (2010) pp. 136.

74 STC 976, Peña Wasaff con Isapre ING Salud S.A. (2007), STC 1248 (2008), STC 1710 (2010).

75 JORDÁn (2013) p. 357-359.

${ }^{76}$ Como se vio, la libertad de trabajo fue el componente principal del derecho constitucional, complementado con el derecho a una justa retribución, entre otros. Hasta ahora, la jurisprudencia constitucional había sido consistente en este sentido, dando cuenta de ello las SSTC 1413 , C. $21^{\circ}$ y 1254 C. $89^{\circ}$, desde la libre contratación, o bien, revisando la existencia de restricciones legales en STC 1133 , C. $30^{\circ}$ y 804 , C. $10^{\circ}-12^{\circ}$; incluso, el Tribunal ha construido la garantía desde el derecho de propiedad (STC 698 C. 9º, letra f). Las STC referidas dan cuenta de cómo el Tribunal ha configurado el derecho al trabajo, principalmente, desde categorías privadas vinculadas a la contratación entre particulares. En este sentido, también se manifiesta parte de la jurisprudencia 
dad del trabajador en la forma en que efectúa su labor y a la ineludible función social que cumple el trabajo" (STC 1852, C. $\left.6^{\circ}\right)^{77}$; esta protección al trabajo comprende las condiciones efectivas de trabajo, las que deben ser equitativas y satisfactorias. A este respecto, la (re) interpretación del texto constitucional es aún más profunda: el Tribunal ha resignificado el contenido de la voz 'protección' presente en el inciso $1^{\circ}$ del numeral en comento. La sola protección de la libertad de trabajo, criterio presente en la redacción del texto original y recogido por la doctrina tradicional ${ }^{78}$, se complejiza gracias a la incorporación de la protección del trabajo propiamente tal, incorporando nuevos criterios de protección constitucional del bien 'trabajo'. Así, sin entrar en la polémica sobre el grado de fundamentalidad del derecho, reconvierte la concepción inicial de la libertad de trabajo en el derecho a la protección del trabajo, asumiendo desde ya su condición de tal. Esta tendencia de la jurisprudencia pareciera consolidarse con una secuencia de fallos que siguen a la STC 1852. Recogiendo prácticamente el mismo argumento, el Tribunal ha afirmado que el art. $19 \mathrm{~N}^{\circ}$ 16 "no se limita solo a garantizar la libertad de elección y de contratación laboral, sino que, al incluir la garantía constitucional el reconocimiento expreso de la libertad de trabajo y su protección, la Constitución extiende la protección al trabajo mismo, en atención al compromiso inseparable de respeto a la dignidad del trabajador en la forma en que efectúa su labor y a la ineludible función social que cumple el trabajo" (STC 2110, C. $\left.8^{\circ}\right)^{79}$. Se trata de un cambio explícito en la comprensión del contenido del enunciado normativo, que amplía la base material de protección constitucional del derecho al trabajo propiamente tal; en esta sentencia, el Tribunal ha reconocido por primera vez el rango constitucional del principio de protección del trabajador ${ }^{80}$, lo que constituye una transformación muy significativa del ámbito de garantía constitucional.

Ahora bien, no es que la Carta 'extienda' el ámbito de protección al trabajo mismo; ha sido el desarrollo hermenéutico del enunciado constitucional lo que ha generado dicha ampliación. Así, el Tribunal Constitucional configura el derecho a partir de determinado contenido material del enunciado, separándose de la concepción inicial en la cual el mismo tenor literal solo protegía la libre contratación ${ }^{81}$. El Tribunal construye dicho contenido desde el reconocimiento de la especial posición del trabajador en la relación jurídica que se regula y en la función social que cumple dicha actividad; de hecho, ninguno de estos criterios formó parte de la discusión en el seno de la Comisión Ortúzar, dando cuenta de cómo evoluciona el contenido de la Carta. Se verifica lo que Guastini denomina una interpretación decisión, en virtud de la cual el intérprete no realiza un ejercicio cognitivo para develar el verdadero sentido y alcance del tenor literal, sino que construye argumentativamente

\footnotetext{
constitucional más reciente (SSTC 2199, 2213, 2186, 2398, 2340) que, sin embargo, ha sido nuevamente contradicha por la STC 2470.

77 STC 1852, Segundo Juzgado de Letras de Talagante (2010).

78 Evans (1986) p. 216.

79 STC 2110, Orellana con Empresa de Transporte Tur Bus Ltda. (2011). En el mismo sentido se han manifestado las SSTC 2114, 2182, 2197.

80 Gamonal (2013) p. 438.

81 Zúniga (2011) pp. 791-798.
} 
el significado del enunciado normativo ${ }^{82}$. Esta distinción es clave para comprender cómo ha operado la mutación en esta materia: la diferencia entre interpretación/conocimiento e interpretación/decisión es la que permite comprender la distancia que existe entre enunciado normativo y norma, entre los cuales media la interpretación. El Tribunal Constitucional se ha separado de la comprensión tradicional en materia de protección de derechos sociales, comprendiendo que del enunciado de los textos constitucionales no se desprende un único contenido correcto posible; al contrario, el eje para la determinación del valor protegido constitucionalmente radica en los argumentos que sustenten o justifiquen la decisión.

Este tránsito también puede ser verificado respecto de los fundamentos teóricos para la protección de los derechos fundamentales de carácter social, concretamente en lo relativo a la dignidad de la persona humana. A este respecto, especial consideración requiere el recurso argumentativo del Tribunal a la dignidad del trabajador como valor que fundamenta la protección de los derechos, que constituye un cambio radical en la construcción del discurso político del período que se inicia en 1973. En efecto, el derecho al trabajo ya no se configura solo desde la dignidad de la persona humana, como da cuenta la doctrina clásica $^{83}$ : el Tribunal incorpora una categoría específica, relacionando el valor constitucional protegido normativamente (el derecho al trabajo), con el sujeto en particular que lo ejerce (el trabajador); así, el derecho ya no es solo desde la dimensión abstracta de la dignidad humana, sino desde la consideración del trabajador en concreto y de las condiciones materiales de su ejercicio. Ello da cuenta de cómo la norma no se agota en el tenor literal del enunciado, sino que se construye argumentativamente a través de su interpretación, atendiendo a la especificidad de los valores constitucionalmente garantizados.

\section{Revalorización del principio de subsidiariedad y la libertad contractual}

El principio de subsidiariedad ha sido sindicado como una de las piedras angulares del diseño constitucional vigente, por cuanto plasmaría determinado modelo que se irradiaría a todos los ámbitos de la actividad económica ${ }^{84}$, entre ellos, también al ejercicio de los derechos sociales ${ }^{85}$. Sin embargo, luego de más de treinta años de aprobado el texto original de la Constitución vigente, y a pesar de la larga hegemonía de la doctrina clásica en la materia, han surgido voces críticas que han cuestionado tanto el contenido como la extensa aplicación que se ha hecho de él por parte de la doctrina nacional ${ }^{86}$, que pareciera tener ya un correlato en la jurisprudencia constitucional.

En efecto, el Tribunal Constitucional interpretó el principio de subsidiaridad a la luz de la fuerza normativa que caracteriza a la Carta Fundamental y en relación a la eficacia y el respeto de los derechos fundamentales, obligación que no solo recae en los órganos del Estado, sino también en los particulares, por cuanto existe un mandato expreso de la Constitución. En esa línea, el Tribunal reconfigura completamente el contenido constitucional de este

\footnotetext{
82 Guastini (1999) pp. 203-204.

83 Plá (1998) p. 334, SÁez (2000) p. 4.

84 Por todos, Fermandois (2006-2011).

85 LOO (2009) p. 420; BASSA (2008) p. 150.

86 Viera (2013); Jordán (2010) y Loo (2009).
} 
derecho social, por cuanto el principio de subsidiariedad ya no puede ser esgrimido como un argumento para garantizar sin más la libre iniciativa económica: en materia de derechos sociales, los particulares (v.gr., Isapres) se encuentra obligados a respetar y promover los derechos fundamentales que se satisfacen mediante sus prestaciones limitando, de paso, el contenido de la libertad empresarial ${ }^{87}$. El Tribunal ha reconocido el efecto de irradiación que caracteriza a los derechos fundamentales en su comprensión contemporánea, efecto que se verifica no solo sobre el ordenamiento jurídico infraconstitucional, sino también en las relaciones entre particulares y en sus actos normativos de efecto particular ${ }^{88}$. Ello ha significado relativizar la preponderancia del principio de subsidiariedad en su aplicación a las relaciones de protección de derechos de carácter social, que ha cedido ante los valores constitucionales de orden público en el ejercicio de los derechos fundamentales.

De esta forma, la obligación que tienen los particulares de respetar los derechos fundamentales se desprende del análisis que el Tribunal Constitucional realiza del derecho a la protección de la salud: la Constitución utiliza la expresión "preferente" respecto al deber que tiene el Estado en su protección. El Tribunal invierte la dimensión obligacional del principio de subsidiariedad, reconociendo que el primer obligado a proteger y satisfacer el pleno ejercicio de los derechos fundamentales es el Estado, siendo los particulares que participan como prestadores meros agentes que actúan en subsidio del Estado: "el establecimiento de este deber significa que el sector privado asume un rol subsidiario en relación con la actividad estatal y no como se entiende en el contexto del orden público económico que ampara la Constitución, en que el Estado se repliega o limita ante el principio de la libre iniciativa o del derecho de toda persona de desarrollar cualquier actividad económica, permitiendo así que los particulares asuman un rol de promotores de esta última" ${ }^{89}$. La actividad que pueda materializar un particular en función de garantizar el ejercicio de los derechos fundamentales, se encuentra condicionada por la dimensión iusfundamental del valor protegido, explicando por qué el efecto irradiación de los derechos afecta a los contratos privados de salud.

La argumentación del Tribunal en materia de subsidiariedad supone un cambio respecto de la concepción tradicional sostenida, por ejemplo, en la STC 352 que fortalecía la dimensión abstencionista del principio, aunque abriendo la posibilidad de reinterpretación respecto de aquellas funciones que, por su carácter, debe asumir el Estado. Sin embargo, la autonomía de los grupos intermedios defendida en STC 352 cede, en STC 976, ante la necesidad de proteger un valor constitucional, el derecho a la protección de la salud, que ya no se explica solo desde la autonomía de los cuerpos intermedios. En este sentido, cobra relevancia la definición del concepto 'potestades públicas', en tanto funciones que la Constitución entrega a determinadas autoridades y cuya delegación resulta contraria a esta (STC 1024). Sin perjuicio que los particulares puedan otorgar prestaciones de salud a través de contratos entre privados, lo cierto es que esta se verifica en el marco del ejercicio de una función pública (la garantía de los derechos fundamentales), la que limita el ámbito

\footnotetext{
87 STC 976, C. 36º, Peña Wasaff con Isapre ING Salud S.A. (2007).

88 JORDÁN (2013) p. 357.

89 STC 1710 (2010) C. $121^{\circ}$.
} 
de libertad en la contratación e invierte, según se ha visto, el principio de subsidiariedad ${ }^{90}$. Este cambio en la aplicación del principio de subsidiariedad se enmarca en un contexto de discusión y reflexión teórico que parte de la doctrina ha impulsado en los últimos años, destinado a revisar los efectos que genera su aplicación ${ }^{91}$.

El Tribunal profundiza esta línea argumentativa y revisa críticamente la aplicación de un principio propio del Derecho Privado, como es el respeto a la autonomía de la voluntad de la partes, en la protección de los derechos fundamentales; en concreto, afirma que el contrato privado se encuentra limitado por las propias garantías constitucionales sobre las cuales versa $^{92}$. El Tribunal reconoce que las relaciones entre privados deben respetar la normativa constitucional y, especialmente, los derechos fundamentales, ante los cuales cede el principio de autonomía de la voluntad: "todas las cláusulas del referido contrato deben orientarse a materializar el goce real y legítimo de dicho derecho"93, sin que el contrato pueda obstaculizar el legítimo ejercicio del derecho. De esta forma, el Tribunal construye la protección de los derechos sociales desde la titularidad universal garantizada constitucionalmente, que se erige como "la base constitucional y de orden público de todo contrato de salud, con plena vigencia en el contexto de dicha convención, razón por la cual esta no puede incluir cláusulas que desconozcan o aminoren" el derecho ${ }^{94}$, "debiendo ser interpretadas y practicadas en armonía con el reconocimiento y tutela del derecho a la protección de la salud"95.

Resulta interesante revisar el contenido de esta sentencia, puesto que a menos de cinco años de su promulgación comienza a avizorarse la consolidación de una línea jurisprudencial que excede el ámbito del derecho a la salud, construyendo una argumentación común para la protección de los derechos sociales en general. De esta forma, la STC 1852 (que abre una línea jurisprudencial en la protección constitucional del trabajo) cuestiona expresamente la facultad del empleador de manejar discrecionalmente los turnos de los trabajadores, en especial cuando ello redunda en una prolongación excesiva de la jornada de trabajo y en una consecuente limitación del tiempo libre de que dispone el trabajador. El Tribunal afirma que ello vulnera los derechos del trabajador, por cuanto lo sujeta a una jornada cuya duración no es vista como razonable, al afectar seriamente su debido descanso (C. $7^{\circ}$ ). Existe una evidente relativización del valor de la autonomía de la voluntad en la relación contractual para la determinación de las condiciones de trabajo, la que no solo deriva de la legislación específica, sino de la propia protección constitucional del trabajo. En definitiva, estamos en presencia de un cambio en la preponderancia de los criterios de interpretación constitucional: la combinación entre la técnica del originalismo y los criterios privatistas han cedido lugar a una hermenéutica no cognoscitivista que se construye desde criterios iuspublicistas que reconocen el efecto irradiación que presentan los derechos fundamentales y su primacía en las relaciones entre particulares.

\footnotetext{
90 STC 976, C. 36º, Peña Wasaff con Isapre ING Salud S.A. (2007).

91 Viera (2013) pp. 196-216, Jordán (2013).

92 STC 976, C. 39º, Peña Wasaff con Isapre ING Salud S.A. (2007).

93 STC 976, C. 64\%.

94 STC 976, C. $43^{\circ}$.

95 STC 976, C. $56^{\circ}$.
} 
Ambas líneas argumentales comparten una matriz común: aun cuando se trata de conflictos constitucionales que surgen de las relaciones contractuales entre particulares, el Tribunal distingue con claridad el interés constitucionalmente protegido para construir una argumentación que lo resuelva. Así, tanto en los fallos de salud como en los recientes fallos relativos a la protección de las condiciones laborales, el Tribunal ha relativizado la dimensión privado/contractual de los conflictos y los ha resuelto en clave de Derecho Público, es decir, desde la protección constitucional de los derechos fundamentales. Sin perjuicio de la existencia de importantes puntos de encuentro, finalmente se trata de disciplinas diferentes que reconocen, recíprocamente, una serie de especificidades, las que se definen al aplicar el Derecho pertinente a cada conflicto ${ }^{96}$. De esta forma, el Tribunal Constitucional identifica con precisión aquellos elementos que, provenientes de otras disciplinas, comprometen el legítimo ejercicio y protección de los derechos fundamentales. Los criterios de protección de la autonomía de la voluntad y de la libertad contractual ceden ante el efecto irradiación de los derechos, en especial cuando los particulares realizan una actividad económica al servicio del deber principal del Estado de garantizar el ejercicio de los derechos fundamentales.

\section{CONCLUSIONES}

1. El contenido normativo de las disposiciones constitucionales no se encuentra petrificado en el texto de la Norma Fundamental, en particular dado que esta se estructura desde enunciados abiertos e indeterminados cuya concreción requiere, necesariamente, de un acto hermenéutico posterior al normativo. En este espacio de interpretación iusfundamental, se abre la posibilidad de una mutación del ámbito de protección constitucional, por cuanto la práctica puede experimentar cambios más o menos significativos, a partir de la consolidación de diversas concepciones de aquello que la Carta protege. De esta manera, lo que la Constitución protege depende, al menos en alguna medida, de cómo se valoran los elementos principales de su iusfundamentalidad, lo que se construye a partir de una interpretación suficientemente bien argumentada.

En el marco del Estado constitucional de Derecho, el fenómeno de la mutación adquiere una significación positiva, toda vez que la indeterminación del texto constitucional puede ser entendido como una garantía de libertad política a favor de la sociedad, que podrá concretizar el contenido de la norma iusfundamental a través de la deliberación democrática en sede legislativa. Ello evita la petrificación del ordenamiento constitucional, cuya radicalización contribuye a la erosión de su legitimidad, toda vez que el dinamismo de las estructuras sociales presiona permanentemente sobre un ordenamiento jurídico que regula dichas relaciones. Este dinamismo puede profundizar la brecha entre normatividad y normalidad constitucional, riesgo que se relativiza ante el fenómeno de la mutación constitucional y la apertura de las normas iusfundamentales.

\footnotetext{
96 En una línea argumental similar, VerGARA (2010) pp. 103 y ss.
} 
2. La protección constitucional de los derechos fundamentales de carácter social, en especial el derecho a la protección de la salud y el derecho al trabajo abordados en la presente investigación, han experimentado una significativa transformación impulsada por la interpretación constitucional en sede jurisprudencial. En efecto, dos grupos de sentencias del Tribunal Constitucional promulgadas entre los años 2008 y 2013, dan cuenta de cómo ha comenzado a consolidarse un cambio en la concepción de estos derechos sociales, que abandona progresivamente -aunque, quizá, no en forma definitiva- la conceptualización que de ellos se hizo en el período que se inicia en 1973 al alero de la Comisión de Estudios para la Nueva Constitución. Esta transformación se verifica en una comprensión no cognoscitivista de la interpretación jurídica, en virtud de la cual el Tribunal entiende que no existe un único contenido posible que se desprenda pura y simplemente del enunciado normativo del texto iusfundamental, lo que le permite argumentar a favor de aquella interpretación que mejor favorezca la protección de los valores garantizados constitucionalmente.

3. La mutación en la garantía constitucional de los derechos sociales en estudio, se estructura sobre la base de una serie de factores que pueden ser comprendidos bajo la siguiente caracterización: los derechos fundamentales constituyen bienes de rango constitucional, razón por la cual su protección se encuentra determinada por un ordenamiento iusfundamental indisponible para los particulares prestadores o contratantes de servicios. El Tribunal Constitucional ha reconfigurado el estatuto de los particulares que prestan servicios para el ejercicio de derechos fundamentales de carácter social, a través de dos instituciones centrales: el efecto irradiación de los derechos fundamentales y la obligación principal del Estado en la garantía de los derechos. Mientras el primero supone reconocer la dimensión de derecho objetivo de los derechos, estableciendo límites tanto al ordenamiento jurídico infraconstitucional como a los contratos entre particulares, el segundo ha permitido invertir la conceptualización tradicional del principio de subsidiariedad, ya que al ser el Estado el obligado principal en materia de garantía de derechos fundamentales, los particulares que participan del sistema lo hacen en subsidio del mismo y, en consecuencia, se someten a un régimen de lo público que les es indisponible en la esfera contractual. La reconfiguración de este estatuto jurídico permite garantizar el legítimo ejercicio de los derechos fundamentales de carácter social con prescindencia de los criterios privatistas de interpretación constitucional, que han quedado relegados a un segundo plano. Así, principios tales como la autonomía de la voluntad y la libertad contractual han cedido ante la jerarquía iusfundamental de los derechos protegidos. El Tribunal Constitucional ha reconocido que este estatuto garantiza bienes constitucionales que protegen importantes dimensiones vitales de las personas, como lo son la salud y el trabajo. El grado de fundamentalidad que les atribuye el ordenamiento constitucional ha llevado al Tribunal a configurar un estatuto que se impone a la libertad contractual característica del derecho privado.

Esta reconfiguración, en virtud de la cual es posible afirmar que se verifica el fenómeno de la mutación constitucional, supone la incorporación de elementos constitucionales ausentes en la interpretación constitucional más tradicional. En primer 
lugar, la consideración de las condiciones materiales de ejercicio de los derechos fundamentales, las que no solo forman parte del espacio efectivo protegido por la garantía constitucional, sino que, además, no pueden quedar a merced de las condiciones fijadas por la libertad contractual de los prestadores de servicios. Ni las Isapres pueden determinar cómo se ejerce el derecho a la salud, ni los empleadores pueden desconocer el ámbito de protección constitucional del trabajador, ampliando el contenido del derecho a la protección del trabajo propiamente tal. En segundo lugar, la explícita valoración de la especificidad de estos derechos fundamentales, que supone reconocer el especial ámbito vital que garantiza la Constitución y que sirve de base para la configuración de su fundamentación; concretamente, el reconocimiento de la dignidad del trabajador como fundamento del derecho al trabajo.

\section{BIBLIOGRAFÍA CITADA}

Ackerman, Bruce (2011): La Constitución viviente (Madrid, Marcial Pons).

Aldunate Lizana, Eduardo (2008): Derechos fundamentales (Santiago, LegalPublishing).

Atria Lemaitre, Fernando (2007): Mercado y ciudadanía en la educación (Santiago, Flandes Indiano).

Balkin, Jack (2007): Original meaning and Constitutional Redemption (Yale Law School, Faculty Scholarship Series, paper 227).

Bassa Mercado, Jaime (2013): "La pretensión de objetividad como una estrategia para obligar. La construcción de cierta cultura de hermenéutica constitucional hacia fines del siglo XX", Estudios Constitucionales, año $11 \mathrm{~N}^{\circ}$ 2: pp. 15-46.

Bassa Mercado, Jaime (2008): El Estado Constitucional de Derecho. Efectos sobre la Constitución vigente y los derechos sociales (Santiago, LegalPublishing).

Bobbio, Norberto (2007): El futuro de la democracia (México DF, Fondo de Cultura Económica).

BÖCKENFÖRDE, Ernest-Wolfgang (2000): "Notas sobre el concepto de 'cambio constitucional"”, en: Böckenförde, Estudios sobre el Estado de Derecho y la democracia (Madrid, Trotta) pp. 181-196.

Carrasco Delgado, Sergio (2008): "La evolución político-constitucional de Chile”, Estudios Constitucionales, año 6 No 2: pp. 301-324.

Cea Egaña, José Luis (2012): Derecho Constitucional chileno (Santiago, Ediciones Universidad Católica).

Comisión de Estudios para la Nueva Constitución (1981): "Informe con Proposiciones e Ideas Concretas (16 de agosto de 1978)", Revista Chilena de Derecho, vol. 8 N 1 (1981).

Contesse Singh, Jorge (2002): "Reglas y principios en Chile: jjerarquía entre los derechos constitucionales?”, Anuario de Filosofía Jurídica y Social, vol. 20: pp. 53-93.

Contreras, Pablo, García, Gonzalo, Jordán, Tomás y Villanueva, Álvaro (2010): "Informe en Derecho presentado ante el Tribunal Constitucional en el proceso de inconstitucionalidad del artículo 38 Ter de la Ley N 18933”, Estudios Constitucionales, año 8, № 2.

Cordero Quinzacara, Eduardo (2006): "La dogmática constitucional de la propiedad en el derecho chileno", Revista de Derecho, Vol. XIX n 1: pp. 125-148. 
Evans de la Cuadra, Enrique (1986): Los Derechos Constitucionales (Santiago, Editorial Jurídica de Chile).

Evans de la Cuadra, Enrique (1999): Los derechos constitucionales (Santiago, Editorial Jurídica de Chile).

Fermandois, Arturo (2006-2011): Derecho Constitucional Económico (Santiago, Ediciones Universidad Católica de Chile).

Gamonal Contreras, Sergio (2013): "El principio de protección del trabajador en la Constitución chilena”, Estudios Constitucionales, año $11 \mathrm{~N}^{\circ}$ 1: pp. 425-458.

Guastini, Riccardo (1999): Distinguiendo. Estudios de teoría y metateoría del Derecho (Barcelona, Gedisa).

HäBerle, Peter (2002): "La Constitución como cultura", Anuario Iberoamericano de Justicia Constitucional, No 6.

Hart, Herbert L.A. (2004): El concepto de Derecho (Buenos Aires, Abeledo-Perrot).

Heller, Hermann (2004): Teoría del Estado (Granada, Comares).

Hesse, Konrad (2011): “Concepto y cualidad de la Constitución”, en: Hesse, Escritos de Derecho Constitucional (Madrid, Centro de Estudios Políticos y Constitucionales) pp. 3-55.

Holmes, Stephen y Sunstein, Cass (2011): El costo de los derechos. Por qué la libertad depende de los impuestos (Buenos Aires, Siglo XXI).

Irureta Uriarte, Pedro (2006): Constitución y orden público laboral. Un análisis del artículo $19 N^{\circ} 16$ de la Constitución chilena (Santiago, Ediciones Universidad Alberto Hurtado, Colecciones de Investigaciones Jurídicas).

JellineK, George (1991): Reforma y mutación de la Constitución (Madrid, Centro de Estudios Constitucionales).

JellineK, George (2000): Teoría general del Estado (México, Fondo de Cultura Económica). JoRdÁn DíAz, Tomás (2013): "El cambio del eje referenciador del derecho a la protección de la salud a partir de la jurisprudencia constitucional sobre el sub-sistema privado de salud", Estudios Constitucionales, año $11 \mathrm{~N}^{\circ} 1$ : pp. 333-380.

Jordán DíAz, Tomás (2010): "El principio de contribución constitucional y la abrogación del principio de subsidiaridad en materia de derechos fundamentales", en Ferrada Bórquez, Juan Carlos (coord.), Estudios de derecho público, Actas de las XL Jornadas de derecho público (Santiago, LegalPublishing) pp. 554-573.

Loo Gutiérrez, Martín (2009): "La disciplina constitucional del principio de subsidiaridad en Italia y Chile”, Revista de Derecho, U. Católica de Valparaíso, N 33: pp. 391-426.

Marshall, Pablo (2010): "La soberanía popular como fundamento del orden estatal y como principio constitucional”, Revista de Derecho, U. Católica de Valparaíso, № 35 : pp. 245-286.

Martínez Estay, José Ignacio (1997): "Acerca de las diferencias entre los derechos y libertades clásicos y los derechos sociales", en Revista de Derecho, UC del Norte, año 4 (1997), pp. 133-140.

Martínez Estay, José Ignacio (2006): "Los derechos sociales", en Pereira Menaut, Teoría Constitucional (Santiago, LexisNexis) pp. 299-312.

Martínez Estay, José Ignacio (2010): "Los derechos sociales de prestación en la jurisprudencia chilena", Estudios Constitucionales, año 8, No 2: pp. 125-166. 
Martínez Estay, José Ignacio (2008): "Los derechos sociales: una reflexión a propósito de la sentencia 976 del TC”, en: Nomos N²: pp. 275-290.

Mouffe, Chantal (2003): La paradoja democrática (Barcelona, Gedisa).

Nash Rojas, Claudio (2011): "Los derechos económicos, sociales y culturales y la justicia constitucional latinoamericana: tendencias jurisprudenciales”, Estudios Constitucionales, año $9 \mathrm{~N}^{\circ}$ 2: pp. 65-118.

Nogueira Alcalá, Humberto (2008): "La evolución político-constitucional de Chile. 1976-2005", Estudios Constitucionales, año 6 No 2: pp. 325-370.

Nogueira Alcalá, Humberto (2009): "Las mutaciones de la constitución producidas por vía interpretativa del tribunal constitucional. ¿El Tribunal Constitucional poder constituido o poder constituyente en sesión permanente?", Estudios Constitucionales, año $7 \mathrm{~N}^{\circ}$ 2: pp. 389-427.

Nogueira Alcalá, Humberto (2009): "Los derechos económicos, sociales y culturales como derechos fundamentales en el constitucionalismo democrático latinoamericano", Estudios Constitucionales, año 7 N²: pp. 143-205.

Palma GonzÁlez, Eric Eduardo (2008): "De la Carta otorgada de 1980 a la Constitución Binominal de 2005”, Derecho y Humanidades, No 13: pp. 41-66.

Plá Rodríguez, Américo (1998): Los principios del derecho del trabajo (Buenos Aires, Editorial Depalma).

Powell, Jefferson (1985): “The Original Understanding or Original Intent”, Harvard Law Review, vol. 98: pp. 885-948.

Rojas, Gonzalo, Achurra, Marcela y Dussaillant, Patricio (1996): Derecho Político. Apuntes de las clases del profesor Jaime Guzmán Errázuriz (Santiago, Ediciones Universidad Católica de Chile) 192 pp.

Ruiz-Tagle Vial, Pablo (2001): "Una dogmática general para los derechos fundamentales”, en Revista de Derecho Público, Universidad de Chile, vol. 63: pp. 179-199.

Sacco Aquino, Sabina (2006): "La Constitución de 1980 como fundamento y origen de una teoría constitucional de la irretroactividad”, en Revista Chilena de Derecho, Vol. 33 $\mathrm{N}^{\circ}$ 3: pp. 479-508.

Sáez Carlier, Felipe y Melis Valencia, Christian (2000): Derecho del Trabajo (Santiago, Editorial Jurídica ConoSur Ltda).

Sánchez González, Santiago y Pereira Menaut, Antonio Carlos (1992): "Los derechos sociales y los principios rectores de la política social y económica”, Revista de Derecho Político, No 36: pp. 257-276.

Sánchez Urrutia, Ana Victoria (2000): "Mutación constitucional y fuerza normativa de la Constitución. Una aproximación al origen del concepto”, Revista Española de Derecho Constitucional, año 20 No 58: pp. 105-135.

Sant'Ana Pedra, Adriano (2012): “Mutación constitucional y concreción normativa: cómo la estrcutura de la norma se relaciona con los cambios informales de la Constitución”, Estudios Constitucionales, año 10 N²: pp. 369-390.

Silva Bascuñán, Alejandro (1997-2010): Tratado de Derecho Constitucional (Santiago, Editorial Jurídica de Chile). 
Smend, Rudolf (1985): Constitución y Derecho Constitucional (Madrid, Centro de Estudios Políticos y Constitucionales).

Smith, Peter J. (2011): “How Different Are Originalism and Non-Originalism?”, Hastings Law Review, vol. 65: pp. 707-736.

Solum, Lawrence (2011): "What is originalism? The evolution of contemporary originalist theory" en: Social Science Research Network. Disponible en: http://dx.doi.org/10.2139/ ssrn.1825543]

SQuella Narducci, Agustín (2007): “Una descripción del Derecho”, Isonomía, No 27: pp. 51-70.

Squella Narducci, Agustín (2001): Filosofía del Derecho (Santiago, Editorial Jurídica de Chile).

Strauss, David (2010): The Living Constitution (New York, Oxford University Press).

Verdugo, Sergio y García, José Francisco (2013): "El (mal) uso de la técnica originalista de interpretación. A propósito del caso de Luciano Cruz-Coke": Revista de Derechos Fundamentales, $\mathrm{N}^{\circ} 10$ : pp. 137-156.

Verdugo, Mario, Pfeffer, Emilio; Nogueira, Humberto (2002): Derecho Constitucional (Santiago, Editorial Jurídica de Chile).

Vergara Blanco, Alejandro (2010): El Derecho Administrativo como sistema autónomo. El mito del Código Civil como "derecho común"(Santiago, LegalPublishing).

Vergara Blanco, Alejandro (1991-92): "La propietarización de los derechos", en Revista de derecho de la Universidad Católica de Valparsíso, Vol. XIV: pp. 281-291.

Viera Álvarez, Christian (2013): Libre iniciativa económica y Estado social (Santiago, Thomson Reuters).

Zúniga Fajuri, Alejandra (2011): "El derecho a la vida y a la protección de la salud en la Constitución: Una relación necesaria”, Estudios Constitucionales, año 9 No1: pp. 37-64.

Zúñiga Urbina, Francisco (2008): "Jurisprudencia del Tribunal Constitucional acerca de derechos económicos, sociales y culturales”, Revista de Derecho, Consejo de Defensa del Estado ( $\left.{ }^{\circ} 20\right)$ pp. 83-109.

ZúNiga Urbina, Francisco (2011): "Comentario a la sentencia recaída en cuestión de inaplicabilidad por inconstitucionalidad del artículo 26 Bis del Código del Trabajo (STC Rol No 1852/2010, de 26 de Julio de 2011)", Estudios Constitucionales, año $9 \mathrm{~N}^{\circ}$ 2: pp. 791-798.

\section{JURISPRUDENCIA CITADA}

STC 352 (2002): Tribunal Constitucional, 15 de julio de 2002 (Requerimiento de Inconstitucionalidad)

STC 976, Peña Wasaff con Isapre ING Salud S.A. (2007): Tribunal Constitucional, 26 de julio de 2008 (Requerimiento de Inaplicabilidad por Inconstitucionalidad).

STC 1273, Valenzuela Márquez (2008): Tribunal Constitucional, 20 de abril de 2010 (Requerimiento de Inaplicabilidad por Inconstitucionalidad).

STC 1287, Fernández Bitterlich (2008): Tribunal Constitucional, 8 de septiembre de 2009 (Requerimiento de Inaplicabilidad por Inconstitucionalidad). 
Bassa Mercado, Jaime / Aste Leiva, Bruno - "Mutación en los criterios jurisprudenciales de protección..."

STC 1288 (2008): Tribunal Constitucional, 25 de agosto de 2008 (Proyecto de ley que modifica la Ley $\mathrm{N}^{\circ} 17.997$ Orgánica Constitucional del Tribunal Constitucional).

STC 1248 (2008): Tribunal Constitucional, 4 de noviembre de 2008 (Requerimiento de contienda de competencia del Juez Suplente del Juzgado de Familia de Peñaflor).

STC 1415 (2009): Tribunal Constitucional, 24 de junio de 2009 (Control de Constitucionalidad del proyecto aprobatorio de Estatuto de Roma de la Corte Penal Internacional).

STC 1710 (2010): Tribunal Constitucional, 6 de agosto de 2010 (Sentencia de Inconstitucionalidad).

STC 1852, Segundo Juzgado de Letras de Talagante (2010): Tribunal Constitucional, 27 de julio de 2011 (Requerimiento de Inaplicabilidad por Inconstitucionalidad).

STC 2110, Orellana con Empresa de Transporte Tur Bus Ltda. (2011): Tribunal Constitucional, 16 de octubre de 2012 (Requerimiento de Inaplicabilidad por Inconstitucionalidad).

STC 2114, Méndez con Buses Ahumada (2011): Tribunal Constitucional, 16 de octubre de 2012 (Requerimiento de Inaplicabilidad por Inconstitucionalidad).

STC 2182, Orellana con Empresa de Transporte TURBUS Ltda. (2012): Tribunal Constitucional, 16 de octubre de 2012 (Requerimiento de Inaplicabilidad por Inconstitucionalidad).

STC 2197, Flores Monardes (2012): Tribunal Constitucional, 16 de octubre de 2012 (Requerimiento de Inaplicabilidad por Inconstitucionalidad).

STC 2199, Sindicato Nacional de Empresa de Transporte Cruz del Sur Ltda. con Transportes Cruz del Sur Ltda. (2012): Tribunal Constitucional, 11 de diciembre de 2012 (Requerimiento de Inaplicabilidad por Inconstitucionalidad).

STC 2213, Sindicato Empresa $N^{\circ} 6$ Social Coquimbo con Empresa de Transportes Rurales TURBUS Ltda. (2012): Tribunal Constitucional, 17 de enero de 2013 (Requerimiento de Inaplicabilidad por Inconstitucionalidad).

STC 2470, Fernández con Compañia JAC Transportes Limitada (2013): Tribunal Constitucional, 2 de diciembre de 2013 (Requerimiento de Inaplicabilidad por Inconstitucionalidad). 